DOI: 10.20472/IAC.2018.043.044

SARA SOUSA

IPC - ISCAC, Portugal

\title{
THE REVEALED PREFERENCE METHODS IN ECONOMIC VALUATION OF ENVIRONMENTAL GOODS: A REVIEW
}

\begin{abstract}
:
The environmental goods and services have often been neglected in crucial decisions affecting the environment mainly because the difficulty in estimating their economic value, since we are dealing with non-market goods and, thus, without a price associated. Nevertheless, the inexistence of prices does not necessarily mean these goods have no value. The environment is a key element in today's society that seeks to be as sustainable as possible, where the environmental assets have both use and non-use values. To estimate the use value, researchers may apply the revealed preference methods. This paper provides a theoretical review of the main concepts and methodologies on the economic valuation of the environment, with particular emphasis on the revealed preference techniques. Based on a detailed literature review, this study concludes that, despite some inherent limitations, the revealed preference methodologies are valuable tools for the economic evaluation of the environment. The main purpose of this study is to contribute to an increased theoretical information on the economic valuation of environmental assets, allowing researchers and policy makers to improve future decisions regarding the environment.
\end{abstract}

\section{Keywords:}

Economic Valuation, Environmental Goods, Revealed Preference Methods, Total Economic Value.

JEL Classification: Q50, Q51 